\title{
Effect of Plug-Filling, Testing Velocity and Temperature on the Tensile Strength of Strap Repairs on Aluminium Structures
}

\author{
A. M. G. Pinto, R. D. S. G. Campilho, I. R. Mendes, L. M. P. Durão, \\ R. F. Silva and A. P.M. Baptista
}

\begin{abstract}
In this work, an experimental study was performed on the influence of plug-filling, loading rate and temperature on the tensile strength of single-strap (SS) and double-strap (DS) repairs on aluminium structures. Whilst the main purpose of this work was to evaluate the feasibility of plug-filling for the strength improvement of these repairs, a parallel study was carried out to assess the sensitivity of the adhesive to external features that can affect the repairs performance, such as the rate of loading and environmental temperature. The experimental programme included repairs with different values of overlap length $\left(L_{\mathrm{O}}=10,20\right.$ and $30 \mathrm{~mm}$ ), and with and without plug-filling, whose results were interpreted in light of experimental evidence of the fracture modes and typical stress distributions for bonded repairs. The influence of the testing speed on the repairs strength was also addressed (considering $0.5,5$ and $25 \mathrm{~mm} / \mathrm{min}$ ). Accounting for the temperature effects, tests were carried out at room temperature $\left(\approx 23^{\circ} \mathrm{C}\right), 50$ and $80^{\circ} \mathrm{C}$. This permitted a comparative evaluation of the adhesive tested below and above the glass transition temperature $\left(T_{\mathrm{g}}\right)$, established by the manufacturer as $67^{\circ} \mathrm{C}$. The combined influence of these two parameters on the repairs strength was also analysed. According to the results obtained from this work, design guidelines for repairing aluminium structures were recommended.
\end{abstract}

\section{Keywords}

Epoxy adhesive, experimental testing, plug-filling, strap repairs

\section{Introduction}

Adhesive bonding as a joining or repair method has a wide application in many industries, including the automotive and aerospace industries. Repairs with bonded patches are often carried out to re-establish the stiffness at critical regions; or at corroded and/or fatigue crack spots. Bonded repairs are quickly overcoming fastening techniques because they do not require drilling of rivet or bolt holes, which creates stress concentrations. Other advantages include a reduction in fretting between the patch and the adherend and the prevention of corrosion. However, the limited understanding of the behaviour of bonded assemblies over the life of structures (including under exposure to extreme temperatures and humidity) and the lack of well-established failure criteria still limits their prompt usage on industry applications, at least without a significant amount of testing prior to implementation [1].

Single-strap (SS) and double-strap (DS) repairs are a viable option for structures damaged at an inner section. By this technique, a hole is drilled at the weakened region to remove the damaged and cracked material, which contains sources for 
the premature growth of damage [2]. For the SS repairs, a circular patch is then adhesively-bonded on one of the structure faces. The SS repairs are easy to execute, but the load eccentricity leads to a substantial transverse deflection and consequent peel peak stresses at the overlaping edges [3]. These, added to the shear peak stresses developing at the same regions due to the differential straining of the repair constituents, justify the small efficiency and temporary character of SS repairs [4]. The DS repairs are based on the same principles, but they involve two patches, one on each face of the structure. These are more efficient than SS repairs, due to the doubling of the bonding area and suppression of the transverse deflection of the adherends [3]. This reduces peel peak stresses and significantly enhances the repair strength. Shear stresses also become more uniform as a result of smaller differential straining effects. Nonetheless, Marques and da Silva [5] showed that stress concentrations still exist at the edges, where crack initiation is prone to occur. However, this problem can be reduced by the use of a taper and a spew fillet at the end of the patch and by the use of a mixed adhesive technique. A two-dimensional (2D) approximation of this geometry is often used for design purposes [4], consisting of the replacing of the hole by a gap between two separated rectangular plates. This geometry, reasonably predicting the stresses of the three-dimensional (3D) repair, is acceptable only for the optimization of geometric parameters influencing the repairs strength [6].

A few studies can be found in the literature about the effect of filling the gap between the plates with adhesive (2D approximation) or hole (3D repair) left by the removal of the damaged material. The numerical work of Campilho et al. [7] addressed this technique by using the finite element method (FEM) on tensile loaded 
2D SS and DS repairs with carbon-epoxy adherends. The strength of the SS repairs decreased slightly with the use of plug-filling due to fracture of the plug prior to failure of the adhesive layer along the overlap, due to the lateral flexure of SS repairs [3]. Conversely, plug-filling significantly increased the DS repairs strength $(\approx 10 \%$ strength improvement), due to the absence of flexure of the parent structure. Soutis et al. [4] evaluated using the FEM the influence of plug-filling on the compressive strength of 3D DS repairs on composite structures. The compressive strength of the repairs reached almost the undamaged strength of the laminates by filling the open-hole of the repair with adhesive, due to the reduction of stress concentrations. Campilho et al. [8] addressed numerically using the FEM and using 3D models SS and DS repairs of composite laminates under tension, compression and bending. A $1.2 \%$ strength reduction was obtained for the SS repairs with plugfilling under tension compared to the unplugged condition, due to a plug/laminate interfacial failure prior to failure in the adhesive layer along the bond length.

Published studies on the subject of adhesives technology revealed that loading rate and temperature effects impact significantly on the mechanical properties of adhesives [9]. Thus, these should be accounted for in the design of bonded assemblies or when developing the constitutive laws of the adhesive to be used in FEM simulations. A number of studies have considered strain rates higher than quasi-static conditions. These include the works of Zgoul and Crocombe [10] and Srivastava [11]. One of the first attempts to model the time dependent behaviour of adhesives was the work of Delale and Erdogan [12], which modelled the visco-elasticity of adhesively bonded joints using Laplace transforms. Malvade et al. [13] studied both experimentally and numerically the nonlinear mechanical behaviour of adhesively bonded double-lap joints in tension for variable extension rates and environmental temperatures. In the work of Zgoul and Crocombe [10], the mechanical properties of a rate-dependent adhesive were estimated. The authors emphasized the diverging yield behavior of polymer adhesives in tension and compression, and on the requirement of using hydrostatic pressure-dependent yield criteria under compression.

High temperatures usually lead to a strength reduction of bonded assemblies, due to a degradation of the adhesive properties [14] and adherend thermal mismatch due to the joined materials have different coefficients of thermal expansion [15]. However, the main factor affecting the strength of adhesive bonds under extreme temperatures is the variation of the adhesive properties [16]. The work of Srivastava [11] focuses on the experimental determination of the tensile strength of adhesively-bonded single-lap joints between titanium and composite adherends under varying conditions, e.g., testing temperatures and strain rates. The increase of strain rate showed a positive effect on the joints strength. The joint strength was found to reduce sharply from testing at room temperature to $100^{\circ} \mathrm{C}$. Adams et al. [17] experimentally studied the performance of single-lap joints at low and room temperatures, emphasizing the significance of adherend mismatch, shrinkage and adhesive properties on the stress state of lap joints. The work by Grant et al. [16] 
provides a comprehensive evaluation of the temperature effects on the strength of adhesive bonded single-lap joints under tension and bending, and also T-joints, both made of a toughened epoxy adhesive and mild steel adherends. Tests were carried out from -40 to $90^{\circ} \mathrm{C}$. An extensive test programme, supported by a FEM stress and failure prediction analysis, was conducted. A reduction of stiffness and strength of the joints was found with increasing test temperature.

In this work, the influence of plug-filling, loading rate and temperature on the tensile strength of SS and DS repairs on aluminium structures was studied experimentally. Whilst the main purpose of this work was to evaluate the feasibility of plug-filling for the strength improvement of these repairs for a specific adhesive, a parallel study was carried out to assess the sensitivity of the adhesive to external features that can affect the repairs performance, such as the rate of loading and environmental temperature. The aim was to obtain a complete understanding of the potential of this adhesive under varying conditions. The testing programme included repairs with different values of $L_{\mathrm{O}}(10,20$ and $30 \mathrm{~mm})$ and with and without plug-filling. The global tendencies of these results were also explained from the test results and fracture modes. An investigation was also carried out on the influence of the testing speed on the repairs strength (considering $0.5,5$ and $25 \mathrm{~mm} / \mathrm{min}$ ). Accounting for the temperature effects, tests were carried out at room temperature, 50 and $80^{\circ} \mathrm{C}$. This permitted a comparative evaluation of the adhesive tested below and above the $T_{\mathrm{g}}\left(67^{\circ} \mathrm{C}\right)$ of the adhesive. The combined influence of these two parameters on the repairs strength was also analyzed.

\section{Experimental}

\subsection{Selected Materials and Surface Preparation}

The adherends and patches were fabricated from a very strong aluminium alloy AW6063-T6, reported by the manufacturer as having a yield strength of $172 \mathrm{MPa}$, which was achieved by artificial ageing. The two-part epoxy structural adhesive Araldite ${ }^{\circledR} 2015$, characterized by a large ductility in tension and shear, was selected for this study. The properties of the adhesive used are presented in Table 1 [18]. The bonding surfaces of the aluminium adherends and patches were cleaned with acetone and then manually abraded with an 80 grit paper. After the mechanical process of abrasion, the surfaces were cleaned again with acetone, and allowed to dry before the application of the adhesive.

\subsection{Geometry and Dimensions of the Repairs}

Figure 1 presents the repair geometries tested in this work: (a) SS repair without plug-filling; (b) with plug-filling; (c) DS repair without plug-filling; and (d) with plug-filling. Plug-filling of the 2D repair consists on filling with adhesive the spacing left by the removal of the damaged material, whilst for the 2D approximation it consists of filling the gap between the adherends with adhesive. The main purpose of this modification was to increase the load transfer between the two adherends 
Table 1.

Properties of the adhesive Araldite ${ }^{\circledR} 2015$ [18]

\begin{tabular}{|c|c|}
\hline Property & Araldite $^{\circledR} 2015$ \\
\hline Young's modulus, $E$ (GPa) & $1.85 \pm 0.21$ \\
\hline Poisson's ratio, $v^{*}$ & 0.33 \\
\hline Tensile yield strength, $\sigma_{\mathrm{y}}(\mathrm{MPa})$ & $12.63 \pm 0.61$ \\
\hline Tensile failure strength, $\sigma_{\mathrm{f}}(\mathrm{MPa})$ & $21.63 \pm 1.61$ \\
\hline Tensile failure strain, $\varepsilon_{\mathrm{f}}(\%)$ & $4.77 \pm 0.15$ \\
\hline Shear modulus, $G(\mathrm{GPa})$ & $0.56 \pm 0.21$ \\
\hline Shear yield strength, $\tau_{\mathrm{y}}(\mathrm{MPa})$ & $14.6 \pm 1.3$ \\
\hline Shear failure strength, $\tau_{\mathrm{f}}(\mathrm{MPa})$ & $17.9 \pm 1.8$ \\
\hline Shear failure strain, $\gamma_{\mathrm{f}}(\%)$ & $43.9 \pm 3.4$ \\
\hline
\end{tabular}

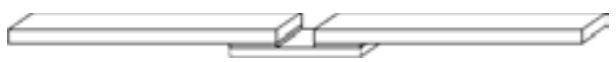

(a)

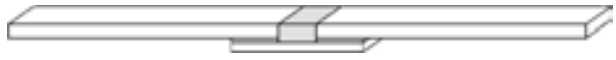

(b)

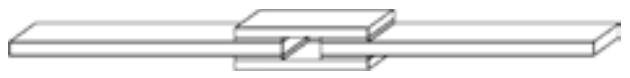

(c)

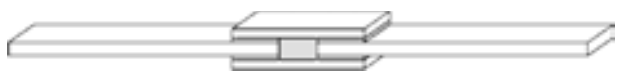

(d)

Figure 1. SS repair without (a) and with plug-filling (b); DS repair without (c) and with plug-filling (d).

[8] originally only achieved by the patches, despite the possibility of a premature plug failure for some of the SS repairs due to transverse deflection [7]. Three values of $L_{\mathrm{O}}$ were studied (10,20 and $30 \mathrm{~mm}$ ) comprising all the repair geometries of Fig. 1. The fixed dimensions of the repairs are outlined in Fig. 2. The repairs were fabricated manually, using a developed device to align the adherends and the patch. The bonding procedure consisted of applying one patch at a time (for the DS repairs) with respective alignment and application of pressure with grips, followed by curing at room temperature for at least $12 \mathrm{~h}$ prior to removal from the device. The desired value of $t_{\mathrm{A}}(0.2 \mathrm{~mm})$ was achieved with fishing lines (diameter of $0.2 \mathrm{~mm}$ ) at the patch edges. The plug was fabricated after bonding of the patch (SS repairs) or simultaneously with bonding of the second patch (DS repairs), using Teflon ${ }^{\circledR}$ plates pressed against the plates with grips. The Teflon did not adhere to adhesives due to Teflon's low surface energy. 


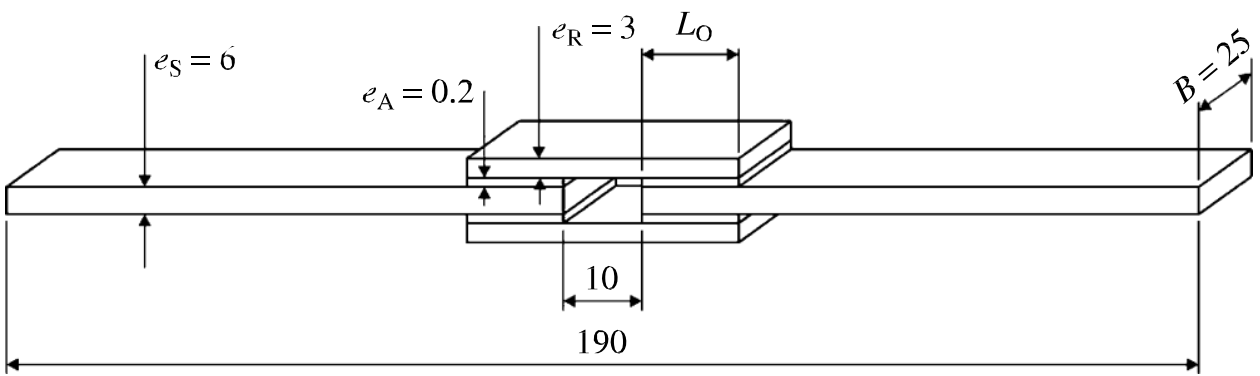

Figure 2. Nomenclature and fixed dimensions of the repairs $\left(e_{\mathrm{S}}-\right.$ adherend thickness, $e_{\mathrm{A}}-$ adhesive thickness, $e_{\mathrm{R}}$ - patch thickness, $L_{\mathrm{O}}$ - overlap length, $B$ - width).

\subsection{Test Conditions}

The SS and DS repairs were tested in tension in a hydraulic testing machine (Instron ${ }^{\circledR}$ 8801) equipped with a $100 \mathrm{kN}$ load cell. Beyond the parametric study of $L_{\mathrm{O}}$, the influence of the testing speed and temperature on the repairs behaviour was also evaluated, considering a DS repair without plug-filling and $L_{O}=10 \mathrm{~mm}$. Testing speeds of $0.5,5$ and $25 \mathrm{~mm} / \mathrm{min}$ were evaluated, which correspond, by the respective order, to shear strain rates of the adhesive of approximately 1.25 , 12.5 and $62.5 \mathrm{~min}^{-1}$. Test temperatures of 23,50 and $80^{\circ} \mathrm{C}$ were considered. This range of temperatures would allow the assessment of the adhesive behaviour below and above $T_{\mathrm{g}}\left(67^{\circ} \mathrm{C}\right)$. The combined influence of the testing speed and temperature was also studied, by considering all combinations between the chosen quantities for these parameters. The reported test values for each condition are the average of four valid tests, except for the tests performed at $50^{\circ} \mathrm{C}$ (only three tests were performed). For the high temperature tests the environmental chamber of the machine was used to attain the desired test temperatures. Before each test, the correct temperature was checked by a thermocouple applied to the specimen. The tests were initiated after approximately $10 \mathrm{~min}$ at the test temperature, to ensure a steady-state temperature throughout the specimen.

\section{Results and Discussion}

\subsection{Strength Dependence with $L_{\mathrm{O}}$}

The $P-\delta$ curves for the SS repairs with $L_{\mathrm{O}}=10 \mathrm{~mm}$ are shown in Fig. 3 (without plug-filling) and Fig. 4 (with plug-filling). The progressive failure of a specimen representative of the above mentioned geometry is represented in Fig. 5 (without plug-filling) and Fig. 6 (with plug-filling), with (a) relating to the unloaded specimen, (b) to the specimen under load and (c) to the after failure condition. Figures 5(b) and 6(b) correspond to a loading of approximately 80-90\% of the maximum load $\left(P_{\mathrm{m}}\right)$, i.e., shortly before failure. It should be emphasized at this stage that all specimens tested, except when mentioned otherwise, failed cohesively in the adhesive layer (Fig. 7). The comparative analysis of Figs 3 and 4 shows a major 


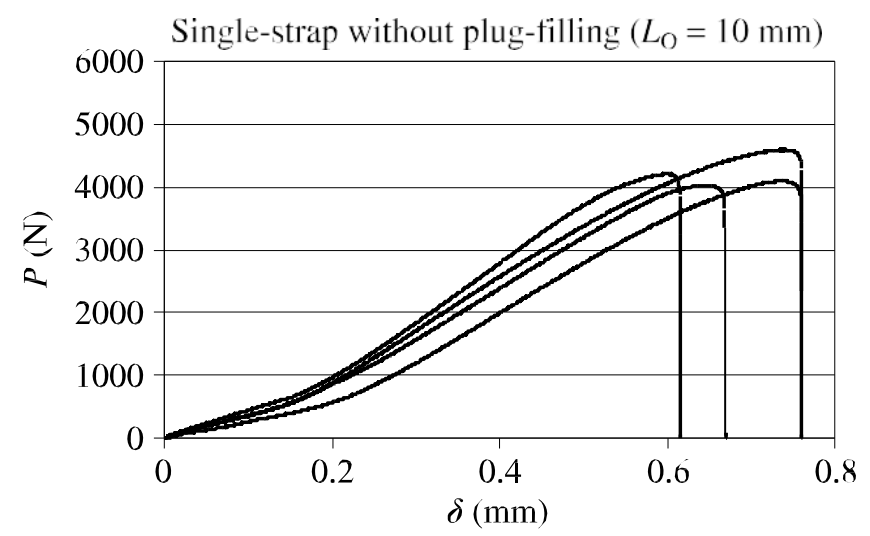

Figure 3. $P-\delta$ curves comparison for the SS repairs with $L_{\mathrm{O}}=10 \mathrm{~mm}$ (without plug-filling).

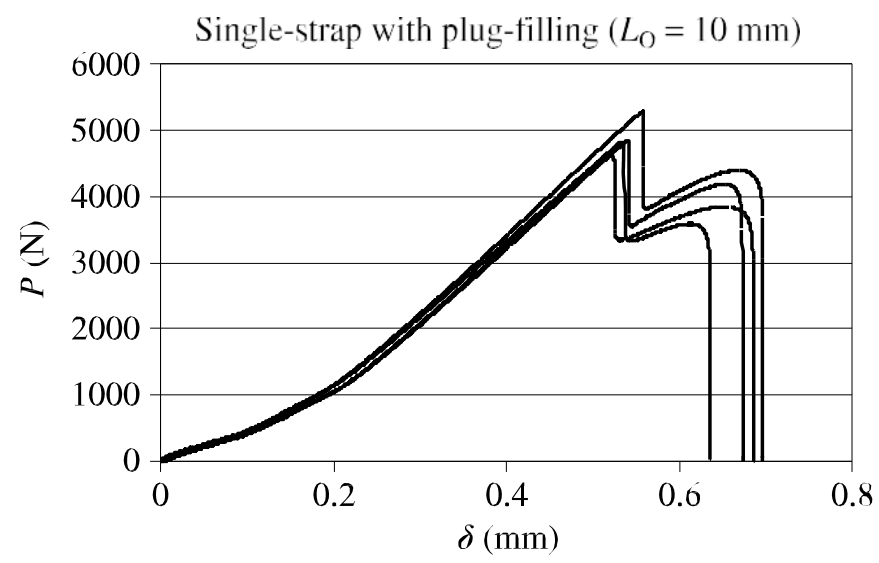

Figure 4. $P-\delta$ curves comparison for the SS repairs with $L_{\mathrm{O}}=10 \mathrm{~mm}$ (with plug-filling).

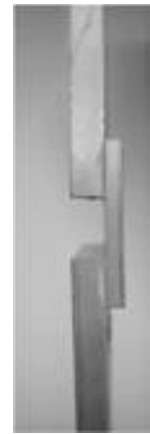

(a)

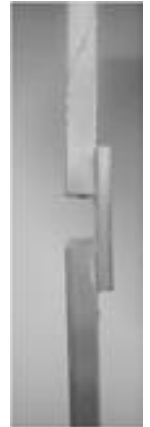

(b)

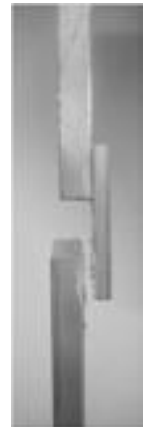

(c)

Figure 5. Progressive failure of a SS repair with $L_{\mathrm{O}}=10 \mathrm{~mm}$ (without plug-filling); (a) relates to the unloaded specimen, (b) to the specimen under load and (c) to the after failure condition. 


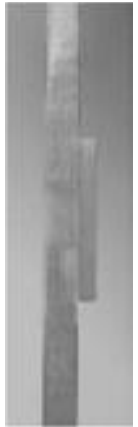

(a)

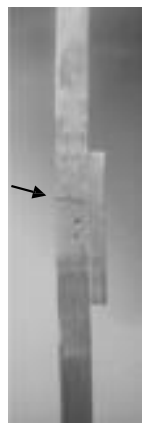

(b)

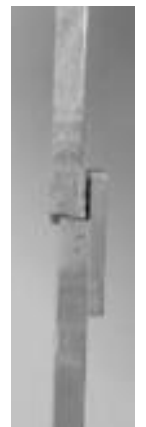

(c)

Figure 6. Progressive failure of a SS repair with $L_{\mathrm{O}}=10 \mathrm{~mm}$ (with plug-filling); (a) relates to the unloaded specimen, (b) to the specimen under load and (c) to the after failure condition.

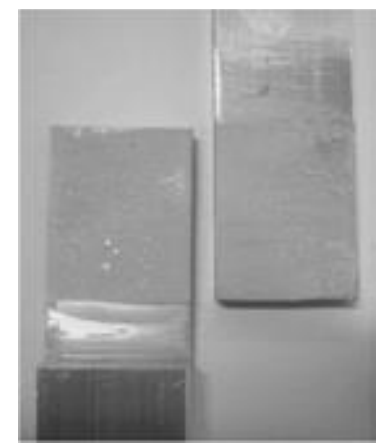

Figure 7. Example of cohesive failure for a SS repair with $L_{\mathrm{O}}=30 \mathrm{~mm}$ (without plug-filling).

improvement on $P_{\mathrm{m}}$ by using the plug. Figures 5 and 6 show the substantial transverse deflection of the repairs, due to the asymmetry of loading that the adherends were subjected to [19]. This was also responsible for the peel stresses peaking at the overlap edges and the consequent weakening of the joints [20,21]. Also visible in Fig. 6 is evidence that the plug-filled repair fails in two steps: in the first one, a cohesive fracture near one of the adherends butts occurred (highlighted in Fig. 6(b) by an arrow) while the overlap was still under load. Subsequently, the repair failed at one of the overlaps. In view of this scenario, it can be concluded that the first step of failure for the plug-filled repair, occurred at a higher load than $P_{\mathrm{m}}$ for the non-plugged repair, which resulted in strength improvement. The subsequent drop of $P$ is due to final failure at the overlap. The values of $P_{\mathrm{m}}$ and deviations for the different values of $L_{O}$ are presented in Fig. 8 (SS repairs). These results show an approximate $15.6 \%$ strength improvement for the $L_{O}=10 \mathrm{~mm}$ repairs by using a plug-filling. For the bigger values of $L_{\mathrm{O}}$, the plug failed at a smaller load than the value of $P_{\mathrm{m}}$ for the standard repair, making this modification ineffective [7]. Actually, the slight differences in Fig. 8 for $L_{O}=20$ and $30 \mathrm{~mm}$ are merely statistical. As a consequence of this behaviour, the positive effect of plug-filling is only notice- 


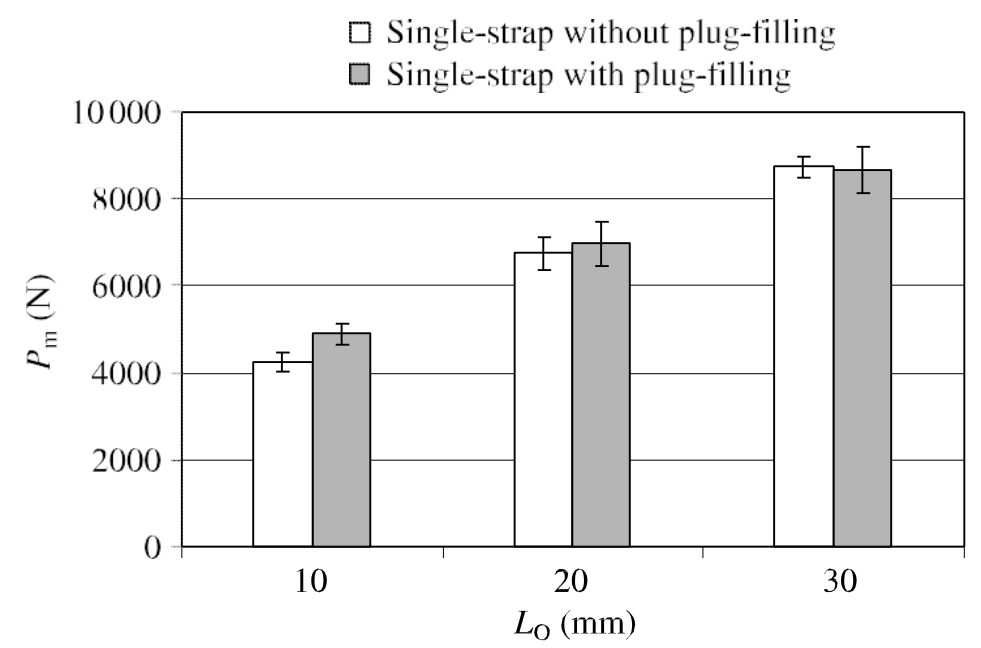

Figure 8. $P_{\mathrm{m}}$ versus $L_{\mathrm{O}}$ plot for the $\mathrm{SS}$ repairs (without and with plug-filling).

able for sufficiently small values of $L_{\mathrm{O}}$, since for bigger overlaps the plug failure occurs prior to the overlap failure. A technique to prevent this premature failure was proposed by Campilho et al. [7] which consisted of reducing the Young's modulus of the plug, leading to a higher flexibility and, thus, permitting an increase of strength. It is also interesting to note a decreasing improvement of $P_{\mathrm{m}}$ with $L_{\mathrm{O}}$, caused by increasing differential straining of the adherends with the increase of $L_{\mathrm{O}}$, due to the larger loads sustained. In fact, whilst shear stress gradients are not important for small values of $L_{\mathrm{O}}$, they do gradually increase, as a result of increasing gradient of longitudinal strains in the adherends [3, 22]. Actually, the adherends are increasingly loaded from their free overlap edge towards the other overlap edge. Since this gradient increases with $L_{0}$ due to the increase of the transmitted loads, as $L_{\mathrm{O}}$ increases shear peak stresses at the overlap edges increase as well [3]. The main reason for the decreasing improvement of $P_{\mathrm{m}}$ with $L_{\mathrm{O}}$ is related to the combined effect of the above mentioned stress gradients with the finite ductility of the adhesives [23, 24]. Actually, for small values of $L_{\mathrm{O}}$ failure occurs under practically global yielding conditions since the stress gradients are small. As $L_{\mathrm{O}}$ increases, the stress gradients increase and the adhesive at the overlap edges fails before global yielding.

An equivalent analysis was performed for the DS repair condition (Figs 9 and 10 show the $P-\delta$ curves for DS repairs with $L_{\mathrm{O}}=10 \mathrm{~mm}$ and without and with plug-filling, respectively). Figure 11 exemplifies the fracture process for both tested scenarios. The repairs behaved approximately linear up to failure for the repairs without and with plug-filling. For the plug-filled repair, this results from a simultaneous failure along the overlap and in the plug (for the values of $L_{O}$ tested). DS repairs were under symmetric loads (Fig. 11), which eliminates the transverse flexure characteristic of SS repairs [3], which causes the mentioned behaviour. 


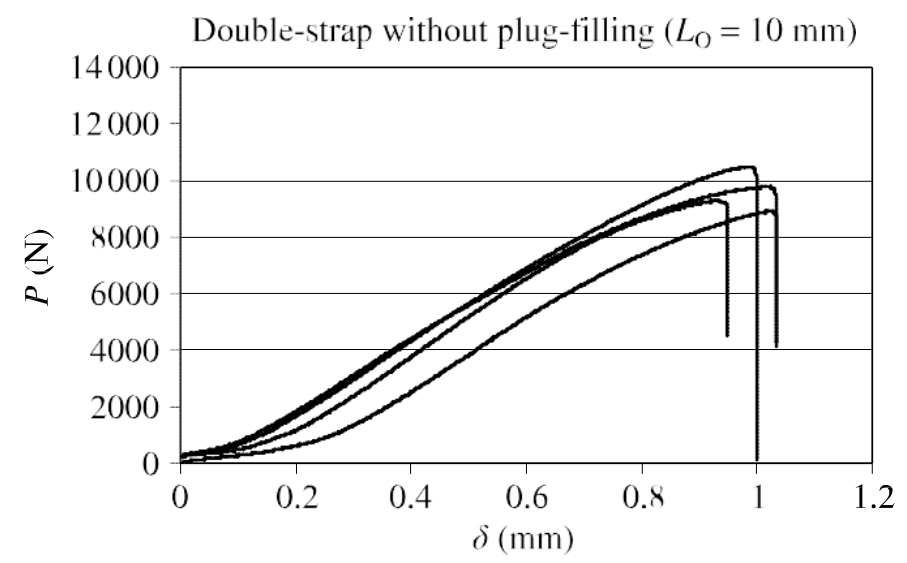

Figure 9. $P-\delta$ curves comparison for the DS repairs with $L_{\mathrm{O}}=10 \mathrm{~mm}$ (without plug-filling).

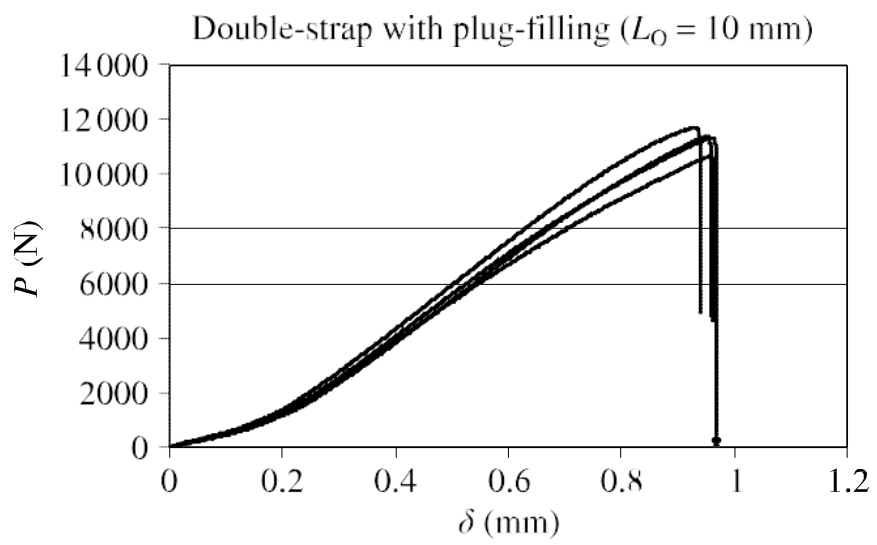

Figure 10. $P-\delta$ curves comparison for the DS repairs with $L_{\mathrm{O}}=10 \mathrm{~mm}$ (with plug-filling).

However, the patches were still under flexure, leading to peel peak stresses in the adherends. Figure 12 shows the evolution of $P_{\mathrm{m}}$ for the DS repairs with $L_{\mathrm{O}}$. Compared to the corresponding SS values (Fig. 8), DS results show that $P_{\mathrm{m}}$ surpassed the double of the SS repairs strength, despite having twice the bonding area. This is justified by the smaller magnitude of peel stresses owing to the absence of the adherends deflection, and also due to the reduction of peak shear stresses at the overlap edges caused by the reduction of differential shearing between the adherend and patches [3]. The increase of $P_{\mathrm{m}}$ with $L_{\mathrm{O}}$ was not proportional, but was closer to being proportional than for the SS repairs, which can be mainly explained by the reduction of peel stresses, added to the aforementioned reduction of differential straining effects, which in turn leads to more uniform shear stress distributions along the overlap [14]. Plug-filling yields an identical absolute improvement of $P_{\mathrm{m}}$ for the three values of $L_{\mathrm{O}}$ since, as previously mentioned, fracture was simultaneous in the plug and overlap, yielding an increase of load transfer. The resulting 


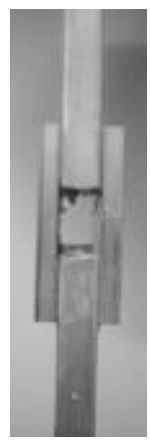

(a)

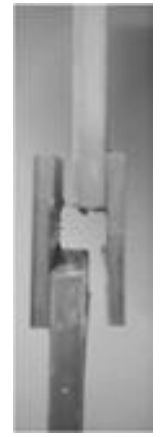

(b)

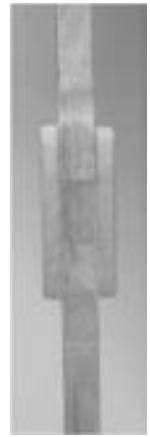

(c)

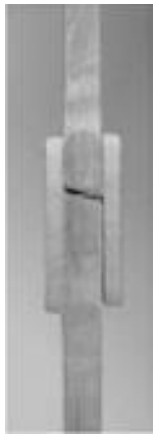

(d)

Figure 11. Progressive failure of a DS repair with $L_{\mathrm{O}}=10 \mathrm{~mm}$ without plug-filling (a and b) and with plug-filling (c and d).

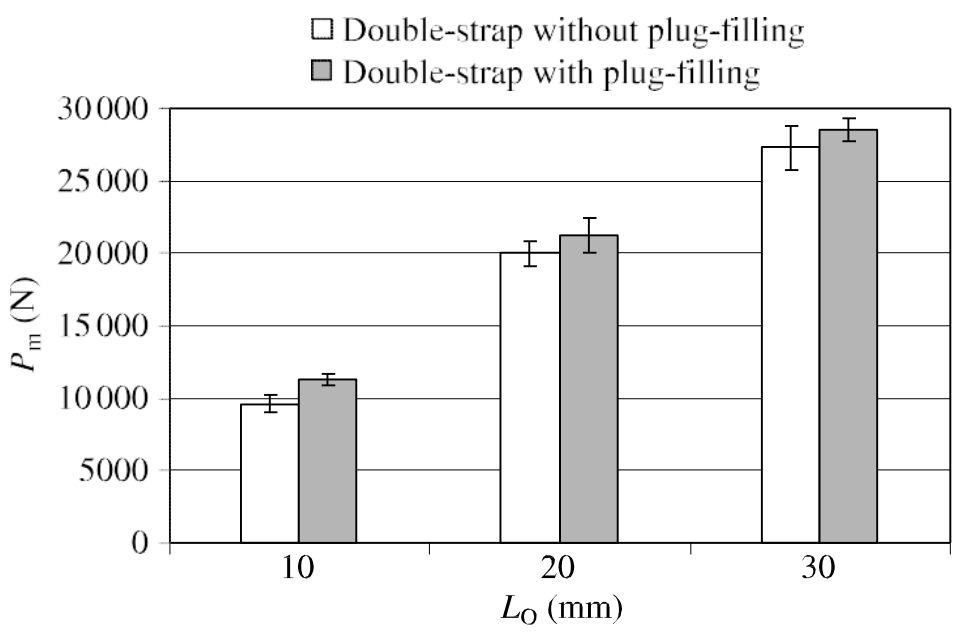

Figure 12. $P_{\mathrm{m}}$ versus $L_{\mathrm{O}}$ plot for the DS repairs (without and with plug-filling).

strength improvement varied between $17.1 \%$ for the $L_{\mathrm{O}}=10 \mathrm{~mm}$ repair and $4.6 \%$ for the $L_{\mathrm{O}}=30 \mathrm{~mm}$ repair.

\subsection{Strength Dependence with the Testing Speed and Temperature}

Figures 13 and 14 plot the $P-\delta$ curves for testing speeds of 0.5 and $25 \mathrm{~mm} / \mathrm{min}$, respectively. The difference in $P_{\mathrm{m}}$ between these two testing conditions, as $P_{\mathrm{m}}$ increases by a significant amount with testing at $25 \mathrm{~mm} / \mathrm{min}$ is evident from Figs 13 and 14. The average values of $P_{\mathrm{m}}$ and deviations are summarized in Fig. 15 as a function of the testing speed (for the three temperatures studied). At all temperatures tested, the value of $P_{\mathrm{m}}$ increased with the testing speed, showing a bigger gradient for the smaller testing speeds (between 0.5 and $5 \mathrm{~mm} / \mathrm{min}$ ) and tending to reach a constant value for bigger testing speeds. This was caused by the increased adhesive resistance to deformation and to molecular displacements with 


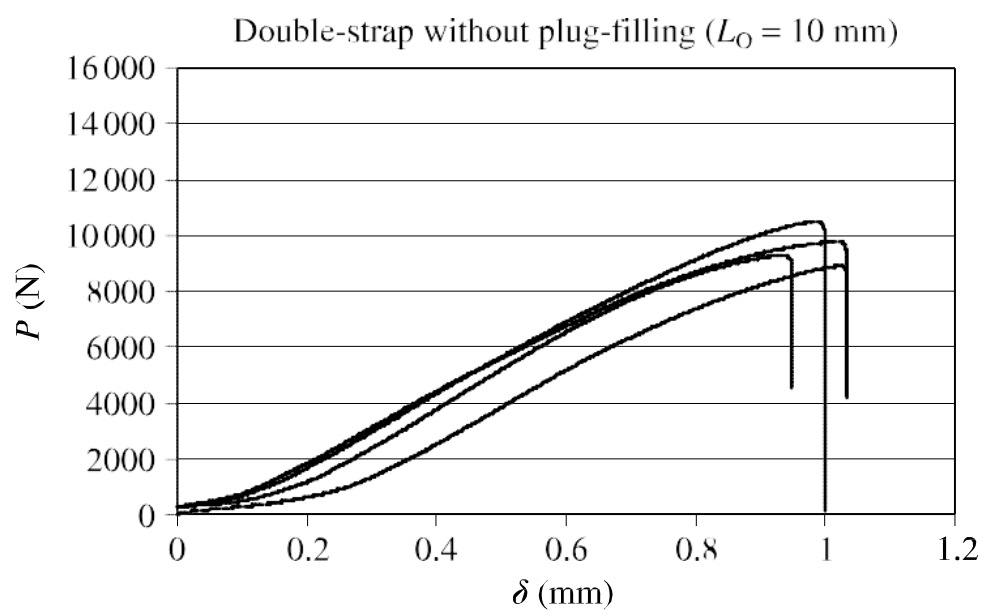

Figure 13. $P-\delta$ curves comparison for the DS repairs without plug-filling and $L_{\mathrm{O}}=10 \mathrm{~mm}$ $(0.5 \mathrm{~mm} / \mathrm{min})$.

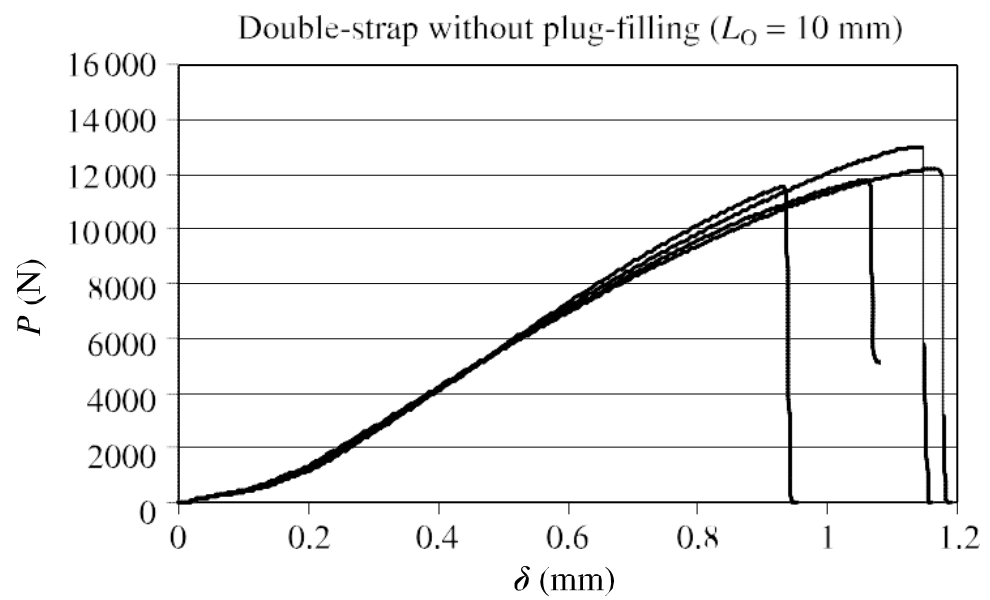

Figure 14. $P-\delta$ curves comparison for the DS repairs without plug-filling and $L_{\mathrm{O}}=10 \mathrm{~mm}$ $(25 \mathrm{~mm} / \mathrm{min})$.

the increase of the testing speed, correspondingly increasing the required load to failure [25]. An identical tendency was found by Zgoul and Crocombe [10], when testing a rate dependent adhesive using the single-lap joint configuration. In fact, as it is generally known, increasing the extension rate is always associated with an increase of the failure load of adhesives, accompanied by a reduction of ductility. The studies at 50 and $80^{\circ} \mathrm{C}$ allow a clear perception of the dependence of the adhesive properties with this quantity, with emphasis on the behaviour below and above $T_{\mathrm{g}}$, established by the manufacturer at $67^{\circ} \mathrm{C}$. Figure 15 shows an increase of $P_{\mathrm{m}}$ at both 50 and $80^{\circ} \mathrm{C}$, but this improvement tends to decrease as the temperature of testing increases. Figure 16 allows the comparison between the $P-\delta$ curves at 50 and $80^{\circ} \mathrm{C}$ 



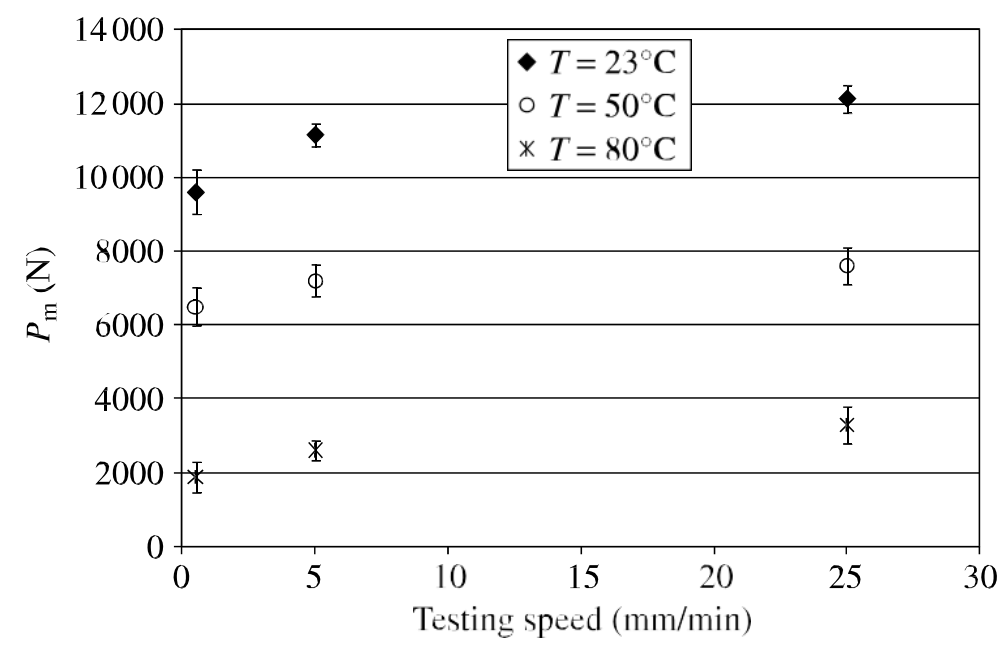

Figure 15. $P_{\mathrm{m}}$ for the DS repairs without plug-filling and $L_{\mathrm{O}}=10 \mathrm{~mm}$ as a function of the testing speed.

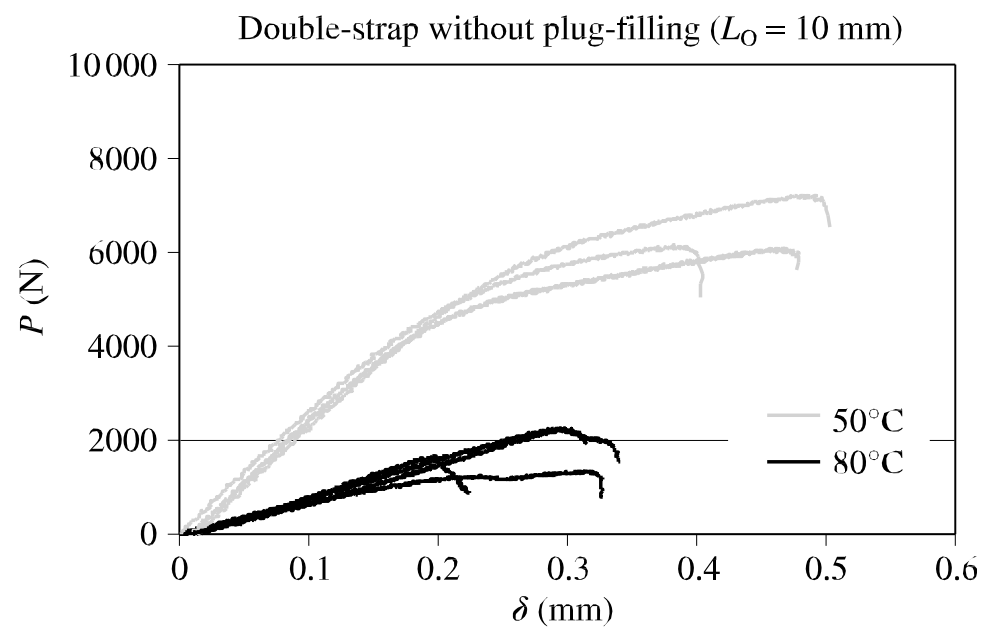

Figure 16. $P-\delta$ curves comparison for the DS repairs without plug-filling and $L_{\mathrm{O}}=10 \mathrm{~mm}$ (temperatures of 50 and $80^{\circ} \mathrm{C}$, testing speed of $0.5 \mathrm{~mm} / \mathrm{min}$ ).

(testing speed of $0.5 \mathrm{~mm} / \mathrm{min}$ ). Globally, the results showed a major strength and stiffness reduction with the increase of temperature, which was expected due to the known degradation of the adhesive properties with the temperature [14]. Actually, upon heating the adhesive, the solid polymer transforms from a rigid to a rubbery state. As a result, the molecules that are virtually frozen in position at room temperature begin to undertake rotational and translational motion. Owing to this, abrupt changes in the physical properties of the adhesive occur. It is also worth mentioning that the fracture was adhesive for all specimens tested at $50^{\circ} \mathrm{C}$ and $80^{\circ} \mathrm{C}$ (Fig. 17), 


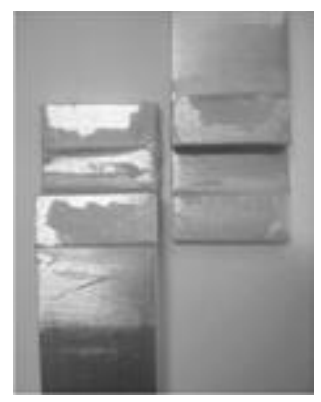

Figure 17. Example of adhesive failure for a DS repair with $L_{\mathrm{O}}=10 \mathrm{~mm}$ (without plug-filling).

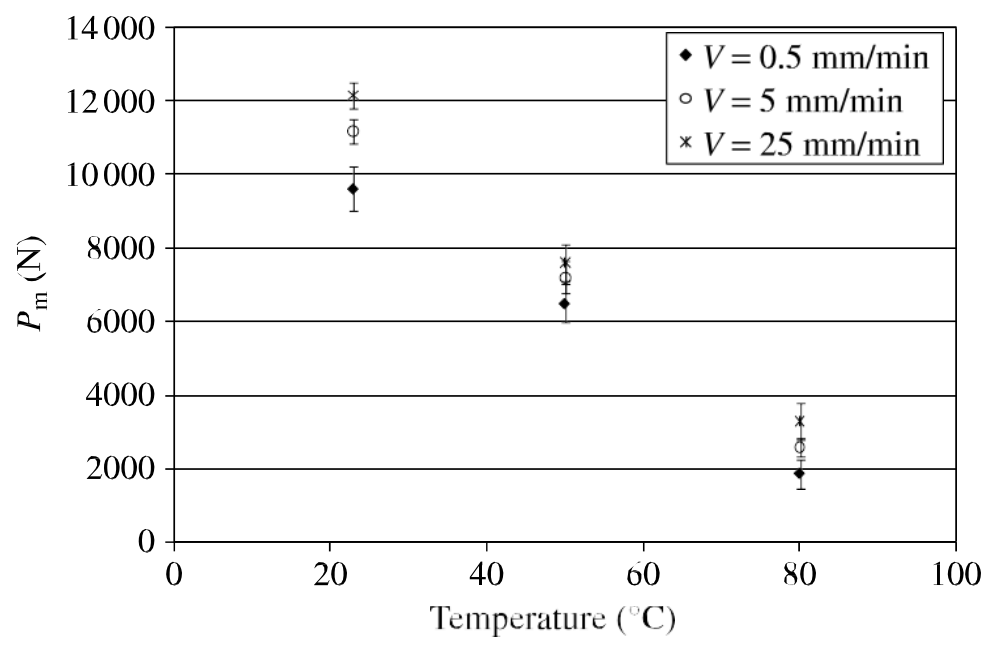

Figure 18. $P_{\mathrm{m}}$ versus $L_{\mathrm{O}}$ plot for the DS repairs without plug-filling and $L_{\mathrm{O}}=10 \mathrm{~mm}$ as a function of the temperature oftesting.

showing the marked degradation of the interfacial properties of the adhesive, comparing to its cohesive fracture properties. Figure 18 shows the data of Fig. 15, but as a function of the testing temperature, emphasizing the expected progressive reduction of strength with the testing temperature and the slight reduction of strain rate effects as the temperature of testing increases. This tendency is consistent with the work of Harris and Fay [26], which addressed the effects of temperature on the strength of single-lap joints for different values of adhesive layer thickness, and da Silva and Adams [27], whose work characterized the properties of a few structural adhesives at temperatures between -55 and $200^{\circ} \mathrm{C}$.

\section{Concluding Remarks}

The influence of plug-filling, loading rate and temperature on the tensile strength of single and double-strap repairs on aluminium structures was studied experimentally. Repairs were tested with and without plug-filling and different values of overlap 
length $(10,20$ and $30 \mathrm{~mm})$. It was globally shown that increasing the overlap length always causes a strength improvement of the repairs, but that this strength improvement is not proportional, mainly due to differential shearing effects between the adherends and patches. Plug-filling of single-strap repairs is to be recommended for small overlap lengths, given that for bigger overlaps, due to the transverse deflection of single-strap repairs, the plug fails prematurely to the overlap. This caused the plug to be ineffective, since at the time of failure the plug was not contributing to the strength of the repairs. Oppositely, for the double-strap repairs an improvement was found for all overlap lengths evaluated. This can be explained by the absence of transverse deflection of the repairs, which caused the plug to be still transmitting loads at the time of failure. An investigation was also carried out on the influence of the testing speed on the repairs strength (considering 0.5, 5 and $25 \mathrm{~mm} / \mathrm{min}$ ). Accounting for the temperature effects, tests were carried out at roomtemperature $\left(\approx 23^{\circ} \mathrm{C}\right.$ ), 50 and $80^{\circ} \mathrm{C}$, to permit a comparative evaluation of the adhesive tested below and above the glass transition temperature of the adhesive $\left(67^{\circ} \mathrm{C}\right)$. The combined influence of these two quantities was also analysed. Concerning the testing speed, an increase of the maximum load was found with this quantity; more significant for the smaller testing speeds and tending to a constant value of maximum load. High temperatures gradually decreased the repairs stiffness and strength due to the degradation of the adhesive, and this degradation is slightly higher at room temperature, reducing at higher temperatures. Principles for repairing aluminium structures were established in this work, which can be extrapolated for other materials and adhesives, although with some cautions since different adherends or patches can yield variations of the stress distributions and, thus, the strength of the repairs. Also the varying allowable ductility of adhesives could probably produce some variation to the results presented here.

\section{References}

1. A. B. de Morais, A. B. Pereira, J. P. Teixeira and N. C. Cavaleiro, Int. J. Adhes. Adhes. 27, 679 (2007).

2. X. Liu and G. Wang, Compos. Struct. 81, 331 (2007).

3. R. D. S. G. Campilho, M. F. S. F de Moura and J. J. M. S. Domingues, Compos. Sci. Technol. 65, 1948 (2005).

4. C. Soutis, D. M. Duan and P. Goutas, Compos. Struct. 45, 289 (1999).

5. E. A. S. Marques and L. F. M. da Silva, J. Adhesion. 84, 915 (2008).

6. F.Z. Hu and C. Soutis, Compos. Sci. Technol. 60, 1103 (2000).

7. R. D. S. G. Campilho, M. F. S. F. de Moura and J. J. M. S. Domingues, Int. J. Adhes. Adhes. 29, 195 (2009).

8. R. D. S. G. Campilho, M. F. S. F. de Moura, J. J. M. S. Domingues and J. J. L. Morais, J. Adhes. Sci. Technol. 22, 1565 (2008).

9. A. D. Crocombe, G. Richardson and P. A. Smith, J. Adhes. 49, 211 (1995).

10. M. Zgoul and A. D. Crocombe, Int. J. Adhes. Adhes. 24, 355 (2004).

11. V. K. Srivastava, Int. J. Adhes. Adhes. 23, 59 (2003).

12. F. Delale and F. Erdogan, J. Appl. Mech. 48, 331 (1981). 
13. I. Malvade, A. Deb, P. Biswas and A. Kumar, Comp. Mater. Sci. 44, 1208 (2009).

14. L. F. M. da Silva and R. D. Adams, Int. J. Adhes. Adhes. 27, 362 (2007).

15. R. D. Adams and V. Mallick, J. Adhes. 43, 17 (1993).

16. L. D. R. Grant, R. D. Adams and L. F. M. da Silva, Int. J. Adhes. Adhes. 29, 535 (2009).

17. R. D. Adams, J. Coppendale, V. Mallick and H. Al-Hamdan, Int. J. Adhes. Adhes. 12, 185 (1992).

18. L. F. M. da Silva, R. A. M. da Silva, J. A. G. Chousal and A. M. G. Pinto, J. Adhes. Sci. Technol. 22, 15 (2008).

19. R. B. Heslehurst, Int. J. Adhes. Adhes. 19, 133 (1999).

20. M. Goland and E. Reissner, J. Appl. Mech. 11, 17 (1944).

21. I. Pires, L. Quintino, J. F. Durodola and A. Beevers, Int. J. Adhes. Adhes. 23, 215 (2003).

22. P. Reis, F. Antunes and J. A. M. Ferreira, Compos. Struct. 67, 125 (2005).

23. L. F. M. da Silva, P. J. C. das Neves, R. D. Adams and J. K. Spelt, Int. J. Adhes. Adhes. 29, 319 (2009).

24. L. F. M. da Silva, P. J. C. das Neves, R. D. Adams, A. Wang and J. K. Spelt, Int. J. Adhes. Adhes. 29, 331 (2009).

25. A. V.Pocius, Adhesion and Adhesives Technology, An Introduction, 2nd edn. Hanser, Cincinnati (2002).

26. J. A. Harris and P. A. Fay, Int. J. Adhes. Adhes. 12, 9 (1992).

27. L. F. M. da Silva and R. D. Adams, J. Adhes. Sci. Technol. 19, 109 (2005). 